\title{
Intimate Visualities: Intimacy as Social Critique and Radical Possibility in Kyle Abraham and Carrie Schneider's Dance Response Project's / am Sold and Blood on the Leaves
}

Stephanie Leigh Batiste, University of California, Santa Barbara

\begin{abstract}
Choreographer and dancer Kyle Abraham and photographer and filmmaker Carrie Schneider position intimacy in screen dance as an affective hailing to viewers. The intimate visualities they achieve serve as an opportunity to critically hypothesize ways of being in community and understanding black visual relationships to subjectivity. In both explorations of meaning a production of close relationships to others, to notions of selfhood, and to blackness animate a radical love of others and of self. Their collaborations, the Dance Response Project, subtly, but powerfully tap persistent modes of black being and of theorizing the social new to creative discourse.
\end{abstract}

Keywords: Black performance, racial gaze, subjectivity, community, selfhood, race, African American

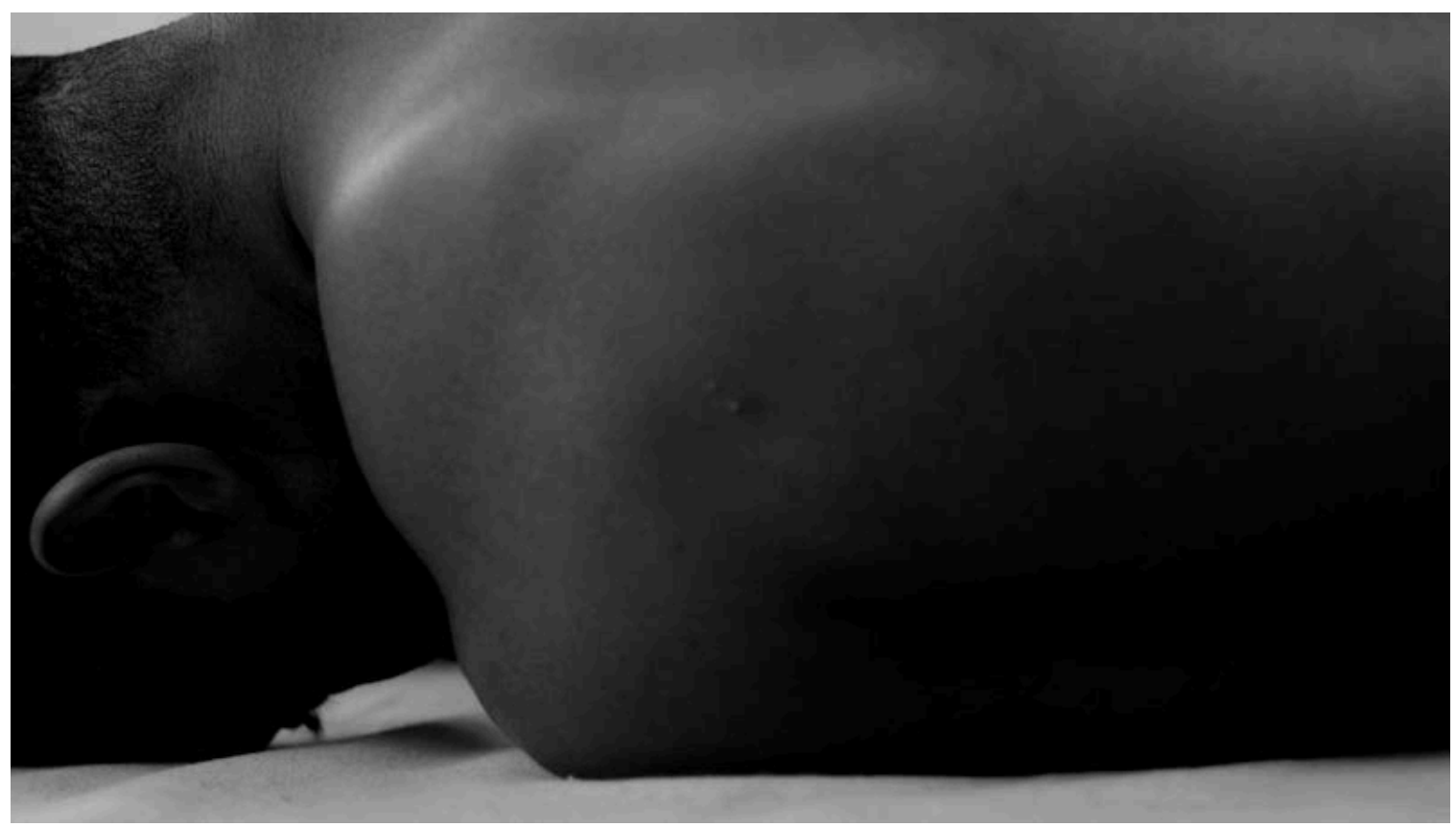

Kyle Abraham in profile, I am Sold, 00:00-00:19, Kyle Abraham and Carrie Schneider, Dance Response Video, 2014. https://vimeo.com/84924942

The International Journal of Screendance 9 (2018).

๑) 2018 Batiste. All rights reserved. 
Kyle Abraham's and Carrie Schneider's I am Sold and Blood on The Leaves turn an intimacy of feeling in cultural production towards a reconsideration of social history and possibility. Dancer and Choreographer Abraham's performance in collaboration with photographer and filmmaker Carrie Schneider' film art create intimacy between the figures and figments in the dance pieces as well as between the filmed piece and the viewer. I am Sold plays lightly on the language of race-based human trade while ironically tapping into the magnetism of giving oneself over to complex love. The play on the word "sold" complicates the capital contract as a history between black and white men that accrues revision. Blood on The Leaves uses complex visual layering that connects and disarticulates lynching, urban violence, and patriarchal misogyny. ${ }^{1}$ The singular form of this piece further connects dance and live performance to mediated consumption. In a manner consistent within Abraham's concert choreography, Blood on The Leaves carries its concern with violence across eras, forms, and media. Kyle Abraham (K/A) and Carrie Schneider's Dance Response Videos film movement and dance as visual art in intimate and intense engagements with race, racial history, racial discourse, and the possibility of transformation. The suggestion of personal and social transformation coalesces in Abraham's multiplying and unifying kinetic address. These screen performances do not romantically, unequivocally take-up a protest agenda. They complicate Black resistance discourses with ideas these are still challenged to incorporate-queer multiplicity, complex physical and discursive legacies of violence, and Black patriarchal misogyny. In this way the work critiques easily identifiable binaries of Black resistance. Abraham and Schneider's work opens discourses of binary oppression to criticism and reorientation via notions of Black community and selfhood.

Likewise, Abraham and Schneider's collaboration challenges binary, staid racist notions regarding a reductive whiteness of the gaze. In my own work on the gaze and otherness in black cultural production, I assert the ways the lookers and subjects can share the gaze, circulating around the camera towards prismatic looking. Collaboration, consent and mutual recognition authorize a prismatic looking that troubles and subverts objectification. ${ }^{2}$ The "darkening mirror" of deep looking at constructed selves also insists on a black gaze that fundamentally refuses the primacy of a hierarchical racialized gaze that prioritizes whiteness as the first and only subject, the first and only consciousness that requires blackness to be its object as if black people are unable to visualize our own subjectivity. ${ }^{3}$ Intersectionally identified, Abraham and Schneider share the gaze in their collaborative film shorts, and as such jettison calcified structures that require and delight in black objecthood. The impetus for the project, the choreography, and the camera's relationship to it are self-conscious and intentional, demonstrating a creative critical relationship of "recognition [that] is actuated and made visible through and across the camera apparatus and in the projected images on the screen." ${ }^{4}$ Schneider and K/A determined aesthetic and lighting choices together as visual context for Abraham's performances. The immediacy of the work derives from Abraham's desire to have "as little premeditation as possible, even refraining from 
listening to some favorite songs for the months leading up to the shoot, so that they could be fresh in the moments in front of the camera. ${ }^{15}$ Schneider found this immediacy to be a key aspect of the collaboration. That is, she valued being unaware of what Abraham would bring and though behind the camera experienced the live improvisation fresh and unplanned. Thus the visual structuring of improvisation and the unexpected secures a measure of liveness to the screen. It, further, upends the primacy of the camera rendering it audience and recipient in its capture.

\section{Haptic Visuality and Intimate Viewing}

These two films in their collaboration of seven were created at an artist residency that did not permit the fellows to tour. ${ }^{6}$ Abraham and Schneider's Dance Response Project was inspired in part by music. The duo "[released] several dance shorts over the course of a year, using [James] Blake's album, Kanye West's recent Yeezus LP, and others." ${ }^{17}$ Unable not to share new work due to the conditions of the 2014 Creative Capital grant they held at the time, Abraham and Schneider designed pieces only for online distribution. Since the pieces were not intended to tour live, the work exploits the possibilities of film and internet viewing to actuate choreography that would be impossible to perform and perceive live on stage. ${ }^{8}$ They deploy the small screen as an intimate, likely, individual encounter that opens minute feeling to broader engagement with complex social concerns. The social experiences of homoerotic, interracial love and inter and intra-racial violence are not only complex, but nearly intractable as taboo, structural violence, and other dividing forces perpetuate paucity of discourse and stymie revolutionary change towards acceptance and peace. Both videos orient themselves to the viewer through a haptic visuality that invites a close sensual interaction with their performances and their significance. ${ }^{9}$ In both pieces, the intimate encounters grow in social significance through Abraham and Schneider's choreography and framing. This collaboration is fairly distinct in Schneider's oeuvre that is more fractal and spare, in a sense, more visually distant and less concerned with the viewer's affective capture. Thus her visual collaboration with Abraham and also with issues of race forged an idiosyncratic visual style imbricated in Abraham's choreography.

The pieces structure a relationship of looking that seduces the viewer into an intimate affective environment created by the dance and the visual engagement it demands. The scopophilic draw envelops the viewer in a tactile sensuality of inter- and intraracial visual and affective touch. ${ }^{10}$ The film's body, the screen, and the viewer's body form a haptic environment where "the particular structures of human touch correspond to particular structures of the cinematic experience." Jennifer M. Barker delineates a "cinematic tactility" that moves beyond the surfaces of both the screen and the skin to activate "fleshy, muscular, and visceral engagement." ${ }^{11}$ More than touch, tactility is a multisensory phenomenological relationship between the environment and the body. Such a tactile relationship in Abraham and Schneider's work compounds the visual 
tactility embedded in the impact of watching with kinetic magnetism between bodies as physical contact and its suggestion in the film. The spare and withheld physical touch creates an unfulfilled magnetism between bodies and, also, between the viewer and the screen. The draw and desire creates an erotic gap where the viewer hovers between desire and autoerotic satiety sharing the camera's unmoving gaze on undulant bodies. Physical touch, its possibility and provocation, becomes a metaphor for affective entwinement that moves ever closer like approaching numbers that endlessly converge. It is a visual attraction subtended by physical and affective desire. The space of desire contains and suggests multiple registers of collective love. Abraham disrupts a controlling relationship between a solitarized viewer and the play on the screen by structuring a diffident multiplicity in the dances. That is, the structuring of company is close and distant allowing the viewer to be drawn in and included in the group. The viewer is one of many participants in the interplay of kinetic and visual attraction.

Through their sensual visual address Abraham and Schneider's internet films manifest the haptic thickness of multisensory engagement with media suggested by Laura $U$. Marks. The haptic suggests touch and multisensory orientation towards and inspired by media where one "presses up to the object and takes its shape" through "tactile, kinesthetic, and proprioceptive" sensibility both on the surface of and inside our bodies. $^{12}$ Marks extends her phenomenological reasoning to the digital despite its apparent immateriality. ${ }^{13}$ Even as the work may be experienced alone in relationship to a device, Abraham and Schneider access an expanded sociality of an, albeit, dynamic and unstable online audience. It is perhaps this solo reception amplified by the "mirror of the screen" through digital visuality that permits a subject's identification with new terms of social understanding that Abraham suggests. ${ }^{14}$

Through their engagement with race, Abraham's performances gently confront history as a screen dance activation queer heterosocial, interracial gaze turned towards an undoing of power. Kaja Silverman explores how "the look" might circulate "independently of the usual sexual boundaries, and without any power to subordinate." ${ }^{15}$ Schneider and Abraham destabilize the look and the gaze by absenting or multiplying it such that the subjectivities on screen resist subordination or otherness towards a shifting active looking within and towards community. Here the undoing of a conditioning primacy of the cinematic gaze develops an orientation away from hierarchical power by emphasizing interiority and with the seduction or drawing in of the viewer as haptic co-participant in the performance. 


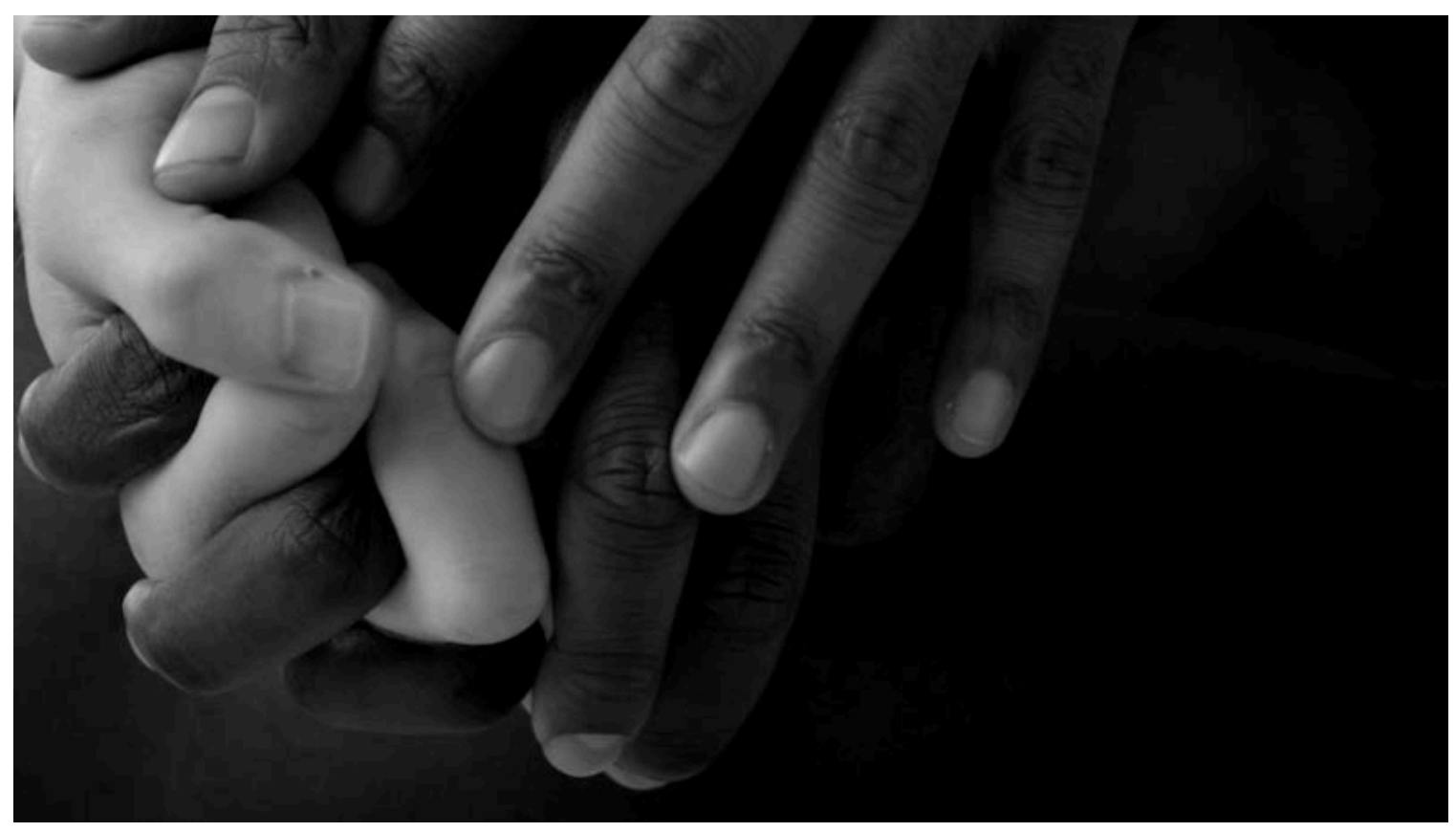

Dancers Kyle Abraham, Maleek Washington, Jeremy "Jae" Neal, Chalvar Monteiro, and Jordan Morley in / am Sold choreographed by Kyle Abraham, produced and directed by Carrie Schneider.

\section{I am Sold- Queer Intimacy as Community}

In I am Sold, Abraham performs with Schneider's camera in black and white in extreme close-up. Interracial queer lovers lay beside each other at ground level against a white background. ${ }^{16}$ In the narrow frame, the viewer sits inches from the skin. In this four minute short performed to James Blake's moody, otherworldly, eponymous song / am Sold, we see men's pores, beauty marks, scars, and pimples on skin and biceps, elbows, shoulders, arms, armpit hair, bare chests, and hips lifting and lying, seeming to hover over and near each other and roll away, replacing each other in the foreground of the frame. The tight steady frame captures the body from the top of the shoulders to the upper hip. There are no heads or faces except in the very opening of the piece when the back of a shoulder and neck of a black man appear in repose against the floor down stage of an ear and lashes in profile, forehead to the floor. His dark face is silhouetted against a white cloth or sheet on the hard floor. This is Abraham. Nude chests, shoulders, and arms move behind and past each other in ocean waves of differently raced dark and light torsos. In the camera's frame the touching and passing of intimate choreography captures a tapestry of closeness and love. Here the gentle proximity suggests intimacy and love in an interplay of safe, vulnerable, confident bodies. The exchange of positions is sexual in that we rarely lay bare-chested next to a partner who is not a family member except in sexual closeness. Blake's opening lyrics, "Link my door tonight, I am Sold" and "You said it was a flash of Green, but you hadn't known" indicate an unexpected lovers tryst, the temporality of the song post-coital during a long night of wakefulness. Yet the 
slow careful exchange of embodied entanglement is neither so private as to expel nor so explicitly suggestive as to titillate. The movement itself is not necessarily sexual. The movement is also not neutral, but more like a sensually charged neutrality of consensual closeness. They trade positions so that one is always lying directly before the camera and behind one's partners, lifting and rolling in and out of the way is romantic in its steady intimacy of non-kin. When one dancer's back faces the camera to fill the frame the suggestion of face-to-face rather than side to side attention amplifies the feeling of intimacy making clear that this gentle moving is about contact and the potential for contact, as well as an enactment of entanglement. The sensuous visual erotic moves under, over, and with the bodies. The performance film's erotic aesthetic emphasizes desire by intimating touch rather than enacting it. The constant smooth interplay of controlled proximity is deeply loving. The nearness and undulating exchange is a willing trade of heart space inhabiting the same consensual sphere with persistence through change. Layers of kinds of love shift and play like the perspectivally layered bodies. Platonic or friendly, and Philio or romantic, and eros or sexual entangle to develop a community-oriented collective agape or unconditional and divine love. Abraham's filmed choreography constructs a queer erotic envisioning that does love work. ${ }^{17}$ This envisioning is queer and black in its involvement of Black creator and subject matter, in its cooperative and collective nature, its centering of erotics, its destabilization of power, and focus on race. In the tradition of the great James Baldwin and Audre Lorde, Abraham offers a pathway to social healing in a vision of queer love, self-love, and loving of blackness and otherness. ${ }^{18}$

I am Sold creates a Black queer vision of deep love through an intense proximity in which the viewer takes part through deep visual contact with homoerotic tenderness. Because of the perspectival layering of bodies the viewer is pulled visually deep into the film's horizon to capture the queer presence of multiple bodies, not a singular or even dual embodiment. With both deep and shallow looking the viewer keeps company in a sensual drawing in. Barker describes a reaching of feeling in which the body gropes toward the screen in an attempt to match the pace of motion displayed and get touched back. The viewer's kinesthetic empathy with the body of the film encourages the viewer not only to mimic the feeling, but further to reach towards it in its impact on the muscles. ${ }^{19}$ Since the bodies touch only hands only lightly and otherwise rarely and barely while in eminently close proximity, the viewer is invited in, to touch skin as barely as the dancers touch, reaching towards and taking part in the potential to connect, to join the dynamic expanding community.

Initially seeming like two people, Black and white skin tones are in fact visible on three bodies, two Black and one white who roll and shift in a tangle. One has to shift one's attention from the foreground to look deep into the horizon of the film to apprehend a third dancer. The population in the scene expands mysteriously with the distant interplay of a third pair of Black hands that appear and lift like an illusion. The presence 
of this third who appears like a narrative twist constructs a polyamorous scene as a conceptual ground for the film's work. Even in its more platonic form the viewer must incorporate an intimate third as already belonging in the sensual community. Even with sound removed contact remains steady and smooth without the thump and thud that might emerge from imperfect balance in reaching bodily across another body in an acrobatic game of twister. Only a muscular strength and quiet precision supports such silent control across tumbling bodies. The interplay is hypnotic. At the end, however, in another twist of plot, the hands of four people layer gently upon each other to interlace and intermingle fingers near the end of the piece, not two and not three. One racially white hand, palm up, on the bottom, is grasped from above by three racially black hands each thumb resting softly parallel upon the preceding hand. The geography of the layering of thumbs and laying on of hands is not possible from fewer than four people. And still the film credits' attribution of five performers further grows the community to yet another active imperceptible participant. The fourth visible hand, another clarifying narrative surprise, perhaps a new participant, offers a placeholder for the viewer's own hand previously unentangled, reaching into and with the performers in the film. Our reaching touch invites us to concur in the film's loving kindness. The fingers tighten slightly and caress almost imperceptibly in front of a prone dark chest that forms the background of the tight focus where the nails and knuckles of the four hands stand out. The fingers release and recede blurring into a fade to black.

The white background of the majority of the performance takes on meaning it would not necessarily have carried prior to these kinetic and visual choices. If the bodies in visual tandem were about the possibility of intimate connection and touch, the accumulation of black hands and medium fade to black extend and emphasize the piece's racial work. While "I am Sold" as a phrase communicates a character of being convinced and of giving over oneself to a person or idea, it also calls up a more violent potential of race-based human sale that is at once healed in a display of interracial interplay and love also substantiated in the cooperation of the film's production. The repeated chorus, "And we late nocturnal, speculate what we feel," invites rumination over the unsettling pressures and insomniac pleasures of sleeplessness. The rest of Blake's lyrics operate like narratives in disjunctive phrases communicating swift emotional shifts much more jarring than the dancers' controlled exchanges. The twisting and turning of thought, danced "late nocturnal," in a waking dream exploring shifting and layered feeling and becoming convinced of a new normal as a satisfying reward.

Nicole Fleetwood describes how performative visions, at times queer, and the visuality of performative blackness trouble dominant visual and power structures. She argues "for the productive possibilities of black subjects to trouble the field of vision precisely by presenting the black body as a troubling figuration to visual discourse." ${ }^{20}$ While manifesting a Black visual structure, Kyle Abraham accomplishes his daring affective 
explorations from the perspective of a Black subject irrespective of a Black or white gaze. The visual discourses he troubles are not always dominant white structures but sometimes dominant Black structures as well. The sexual vulnerability of the interracial male players renders them both open and closed to each other in homo-social and homosexual giving and self-protection. Whiteness appears behind and between an interplay of black bodies that dominate in the visual field. Together the sexual and racial narratives disrupt visual and hetero-normative schemes of racial power. Abraham's fades to Black always seem to suggest a Black normal and blackness as possibility especially in / am Solds conditions of a dominant Black sociality.

The shift in the color of the background from and immaculate white to a pure black offers a shift in terms of the grounds of love and community. After more Black hands embrace the white hand the background shift hypothesizes, likewise, a shift in the social and emotional ground against which interracial love is considered. The accumulating Black hands grow the presence of blackness black love and black acceptance. The white prone hand, palm up at the bottom of the grasp accepts the terms of this caress in an equally gentle grasp. His participation in a loving sociality where he is in the minority serves as an antiracist gesture that relinquishes white privilege. The directionality of interraciality set by the terms of desegregationist integration is discursively shifted and settled within a black spatial reality always already there. A community is formed where a prone and disempowered white hand is in the minority and accepted as lover and as a member of a tight enfolded and multiplying community. The homoeroticism of the piece subtends a community oriented layering of homosocial platonic love with erotic love and social love. I am Sold extends affection as and through gay love towards a broad model of social possibility. Given the persistence of homophobia and racism, / am Soldrenders a brave and bold love also a gentle love; its radical nature not so, but rather a whisper of easy possibility. It is a whisper with earthshaking consequences in its imposition of ease. I am Sold offers a heuristic for Blood on The Leaves queer envisioning of Abraham multiplying in community with himself in contemplation of legacies of violence against Black people.

\section{Blood on the Leaves - Intimacy of Expanding Selfhood and Redress of Violence}

The intimacy and love in / am Sold also appears in Blood on The Leaves as an interplay of self that Abraham and Schneider achieve in positioning Abraham dancing over and with other dancing versions of himself. Abraham dances four improvised takes to the song in Blood on The Leaves' filming. With four independent performances Schneider reports being unable to excise any of Abraham's dancing in the construction of the film, and so layered these four takes in triplicate connected at "moments when there were striking overlaps, where variations on theme emerged and complicated the story." The multiple performance responses and their layering, in turn, multiply the body in a 
critical troubling of historical triplication in the music that drives the work. That Abraham performs four non-characteralogical engagements with the song and its three sonic elements allows any and all of the dance response renditions to represent and respond to the elements and to the whole. The "fourth" improvisatory response always gives K/A an active overarching critical say. His engagement is responsive and assertive, direct and encompassing.

The intimacy of Abraham's multiplied dancing and self-looking are particularly powerful in its irony as Blood on The Leaves treats disturbing violence. Through this complex formal layering Blood on The Leaves concern with black loss, mourning, and the possibility of peace are also multiplied from the site of the body across forms of dance, film, and digital media and as material and intangible spaces. Abraham dances alone in his signature black t-shirt and pants. First appearing alone we soon see Abraham dancing similar, but never simultaneous, choreography layered atop his already kinetic body. He appears once more until he dances with and upon himself in triplicate. The tripling corresponds to three songs mashed together in Kanye West's eponymous composition and rap song Blood on The Leaves. ${ }^{21}$

Always aware of the sonic, historical, and social complexities of music, Abraham works with carefully curated, impactful sound. Kanye West's Blood on The Leaves composition includes two songs iconic of particular eras of violence and emotions surrounding them. Strange Fruit was sung by Billie Holiday penned by Jewish writer Abel Meerpol in the late 1930s and first performed at the leftist Café Society. C-Murder featuring Snoop Dogg and Magic, Down 4 My Niggas cuts into the narrative as West hollers, "We coulda been somebody." West's himself cites C-Murder and raps about interpersonal violence across the historical samples to offer a narrative arc that connects and juxtaposes eras and feelings of violence and loss. By focusing on multiply violated murder victims, Holiday excoriates southerners' depraved white-supremacist lynching practices that were condoned by the U.S. government and society. Holiday's haunting wail protests racist torture and its physical and symbolic oppression. As an interracial protest song, it revised the terms of social optics on violated black bodies and our orientations towards domestic terror in the interest of social change. In a radically contrasting orientation, $C$ Murder's Down 4 My Niggas is a rousing call to neighborhood allegiance and profane destruction of "other niggas" affiliated with another gang or set. ${ }^{22}$ Listeners familiar with the song will conjure the barreling, gravely voice of the speaker who declares, "fuck them other niggas...// ride for my niggas.../I die for my niggas/" in a repeating chorus couched by aggressive verses outlining masculinist loyalty and murderous gunplay. The song's energetic pleasures are sustained in repeated imagining of drive-bys, gunshots, bleeding heads, and other forms of injury, death, and misogynist insult. West's own lyrical overlay speaks of urban economic struggle and heterosexual relationship woes to a forceful bass. West's narrative decries the impacts that women's claims to men's finances and emotions exacted through pregnancy and lawsuits. The song reduces 
Holiday's "Leaves" the word "please" as if begging for West's speaker's life. West's masculinist misogynist self-pity adds a discursive violence to his appropriations of Holiday and C-Murder. West links lynching and gang violence as related murderous, anti-black practices, while ultimately positioning them as background to black men's treatment by black women in the club and the courts. West's gang sets from "Down 4 my Niggas" become Black men and women. That is, West places Holiday and C-Murder in service of a "lynching" of Black men by Black women in custody courts. West's work offers disjunctive parallels between unequal things rendering a musical discursive violence not only to Black pasts, but also to women. The movement and visual structure of Abraham's piece addresses and troubles the orientation of violence in each element of the song and across the composition. Abraham offers the lie to West's composition complicating the sonic relationship to history and re-cutting a contemplation of violence through visual narrative and dance. Abraham's address of the song is layered in its attention to the parts and problematizing of their relationship to each other. K/A brings a critical affective engagement to both by kinetically splitting its layers apart. His multiplying self animates the shattering of violence and also the disturbing split and multiplying of discourses towards greater violence.

West's track mixes and cut sounds and rhythms to achieve a groove that is echoed and revised visually in Abraham's coordinated and contrapuntal dancing. Abraham inhabits Blood on The Leaves to depart from and reinterpret its self-serving misogyny using its own troubling connections. Alongside West's juxtapositions Abraham queries the status and generational transfer of violence. He enacts a historic disjuncture and, in his multiplying self, also questions the shifting role of black people as victim and perpetrator, as creator and critic of violence. Both sound and motion participate in Gaye Johnson's characterization of history as a hip hop technology of beat juggling. She explains,

Beat juggling isolates drum and snare hits, vocal phrases, or sound effects by the recording artist and "flips" or combines the sound with a cross fader; turntablists take what is already contained in a record to create new rhythmic patterns... One sound alone, or the work of one DJ or sound in the form of his beat jugging, means very little until it is joined with other sounds and results in a collective sonic production...DJs must be masters of both mixing and memory. ${ }^{23}$

Abraham joins West in a sonic historical and kinetic juggling of narrative, sound, and motion to bring disparate moments and feelings together into new composition. Yet, the fundamental drive towards collectivity in Johnson's notion of historical re-mixing fails to appear in West's Blood on The Leaves. K/A's composition moves at odds with and in contradistinction to West's uses of sonic history. West and Abraham's layered temporalities emerge from manipulated rhythms to radically different ends. With the introduction of each voicing and sample, a new dancing Abraham appears in the frame. 
Through these appearances Abraham embodies the shattering impact of violence. He calls out and confronts the crises articulated in the song in redress of West. As such, K/A draws our attention to the disparate ends of creative expression in relation to histories and legacies of violence.

The consistency in Abraham's choreography between selves places the phases of the song in problematic conversation with each other. Each song element is scored with similar movement, not different or differently paced choreography, yet not looped. Abraham does not craft kinetic characters that correspond to the samples. Thus the Dance Response asks the samples to remain in conversation, to reflect and respond to each other through a consistency in motion. That Abraham rhythmically connects such disparate musical samples in a consistent and fluid choreography is remarkable. It means that as the three apparitions of K/A dance, the viewer is unable to attach a particular layer to a specific aspect of the song. We must accept a totality. Further, the dancer's kinetic presence amidst the dark narrative of the merging of three songs both embodies each story while also inhabiting the dark spaces between them. In part the consistency in the nature and, at times, repetition of movement facilitate the sense of Abraham slipping between the elements of the song.

Abraham appears out of the black the layering of his black clothing upon a black background causes the chestnut tone of his skin to shine out of the darkness. In each of never more than three layers that fade and return in random relief, Abraham dances before Schneider's still camera. The perspective in each frame is perhaps closer and more magnified as a layer cuts in and out with Schneider's editing. The frame is controlled by Abraham's choreography as it shrinks and stretches with his moves towards and away from the camera in the dark space; his re/appearances as overlay or backdrop in the film's layers. Abraham stages an intimate consideration of himself and of the black selves articulated in the song/s. Schneider layers visual intensity in the kinetic engagement with the problematic terms of history, identity, and creativity. An interplay of tense, fast, and casual movements shift from brief frenetic tension to lithe, effortless sway in the pace of the everyday. A tight core, lifted chest, and shoulders permit the signature blend of strength and rest. Abraham's gaze is down or outward his eyes not focusing on any particular thing, not meeting the camera and not calling to his own gaze in his accruing apparitions. His expression consistently bears a not-quiteneutral concern, not quite judging but clearly engaging the subjects of the song that draw his kinesthetic attention. Abraham repeats a signature gesture where his arms lift his elbows to parallel with his shoulders, hands relaxed, propelled from his back like wings lifting, unable to take flight. The movements of his other selves layer in rhythmic coordination. His eyes and faces never meet. His dispersed attention addresses Black history, Black suffering, and Black selfhood in a troubling of West's toxic Black masculinity and patriarchy. Even when his lifted chin intimates awareness, his consciousness of his other selves is affective and choreographic. His triplication and 
simultaneity connect and multiply his being and his attention. He moves and looks in several directions at once. He is searching and knowing, calling the viewer's attention without confrontation. Schneider and Abraham unite the subject of abjection with the self-active agent in critical conversation with history. As such, Abraham takes on and channels the body of community in his multiplying critical self, confronting for all of us the damages of history and hate.

In some ways the splitting and dispersal, approach and retreat are disturbing as the dancing accompanies the foregone and impending racist death and urban belligerence narrated in Holiday and C-Murder. The feelings evoked in these mini-scenes shift swiftly matching in pace both the faster movements and their smooth transition to the slower ones. The spaces between his appearing and disappearing animate anxiety and anticipation. As a viewer navigating the emotional shifts, we await and anticipate his reappearances, miss him when he goes, hope he will return, feel relieved when he does. Schneider replicates for us a visual desire not to miss a movement, to capture and imbibe more. Thus even in a consideration of violence the visual relationship structures drawing in rather than alienation. The repeated absences and returns open and close a melancholic fear of loss and longing for the dead. Abraham's layers shift towards and away from the viewer at different magnifications as different distances. His appearances offer both closeness and retreat in unexpected overlay. We witness a moving through a sounding of violence without witnessing violence. The impact of the violence is precipitous, though unseen instituting a new visual relationship to spectacular Black associations with violence. The viewer engages visually with a multiplied engaged critical subjecthood cut, mixed and re-constituted.

Marks notes that "what digital video loses in indexicality, it gains in flexibility." ${ }^{24}$ In this digital envisioning Abraham takes advantage of the ability to detach from and multiply his relationship to himself. Abraham is himself and not himself; is himself and greater than himself; is the moment he embodies and hovers between and beyond the phases the music suggests. He hovers in the spaces between the projections of himself. The three Abraham's maintain the simultaneity of the three songs, three eras, and three affects that synchronize and split, separate and realign stretching his and the viewer's affective and temporal relationship to shifts in violence against and by Black people. Abraham's embodied manifestations on screen and ghostly ethereal hovering through his disappearances and reappearances visualize Jennifer Deger's "shimmering" embodiment that refers to the relationship between the viewer and the screen as a "dynamic and transformative space of betweenness." ${ }^{25}$ Abraham suggests and inhabits that between space both on and beyond the screen. Like the seductive visual relationship in / am Sold, Abraham's kinetic visual calling up and habitation of the between space redoubles the film's pull on the viewer towards its historical affective intervention. Deger's notion that this is a "mimetically charged space between the subject and the Ancestral" accrues a slight revision as Abraham's shimmering 
suggestion is not one of mimesis, but itself one of revision and transformation. The haunting affective environment calls us to reconsider and remake conditions of violence confronted by earlier generations with love and to question its complex inheritances. As an historical echo and ancestral project, divisive and annihilating early 20th century and millennial articulations of murder and misogyny come in for eradication and change through $\mathrm{K} / \mathrm{A}^{\prime} \mathrm{s}$ response.

Abraham's movements are quick, yet the overall effect is calm. The dance resonates like multiple chords played on three identical instruments differently at the same time. Thus other seeming impossibilities beyond Abraham dancing with himself emerge out of the darkness in being. The choreography, music and visualization achieve a mashing and simultaneity of time and history; the crisis of mourning and resolution; a contrapuntal interplay of frenzy and calm. There is preparedness and intrepid address in Abraham's lifted chest and chin. The up-pace of the swift movements heighten concern, fear, and despair about death and its misapprehension. The immediate decelerations to tentative stillness suggest falling disorientation and simultaneously a refusal to submit to the terms of any of these articulations of violence. The slower pacings suggest affective transition and contradiction: like shock towards intention, and confusion towards clarity. What also seems to emerge is the possibility of change in and out of layers of violent histories. The body of the dancer animates the creative potential of address and thus the creative possibility of change in a rejection of violence and its circumstances. Possibility is sounded and purveyed in the stillness that exudes this unsettling and complex piece.

The layered composition allows each movement to interact like notes in a melody, each gesture a chord. The contrapuntal play of gazes and gestures composes a song of visual kinetics. The film editing allows Abraham to fade in and to recede, leaving him in kinetic conversation with himself only to strike up a new movement from another part of the screen. The viewer's gaze expands and narrows, shifts, broadens, focuses in again to encompass and embrace collectively the individual dances. Abraham himself looks down and looks out. His gaze never lands. His outward look is universal, rendering his introspection universal as well. The tension between universality and concentrated introspection structures an invitation to share that intimate interiority with him. The viewer hovers with him in his tempestuous multiplicity. We reach towards and between his selves. His proximity to himself animates the potential for touch much like / am Solds alternating waves of flesh. If as Laura Marks reveals, erotic "yielding and being touched are the route not to shattering, but to transformation," Abraham's yielding to his own and the viewer's contemplative company opens a conduit between shattering violence and healing or change. ${ }^{26}$

An auto-eroticism and self-love of scopophilia becomes enfolded as Abraham dances with his visual self and the viewer dances and desires towards him. ${ }^{27}$ Abraham mourns and loves with his danced selves and the viewer, who slips with the ghosted selves into 
the between spaces of love, loss, and violence. The suggestion of a personal self-love is racialized in the gentle, haunted treatment of violence against Blacks by white and Black perpetrators; the provocation is to love Blackness instead of killing it. The viewer's participation in the between spaces inducted by the layered dance draws them into the autoerotic possibility of loving Blackness.

Blood on The Leaves both ghosts and multiplies the self. In this sense its motion implies proprioceptive amplification and proprioceptive loss. The tactile relationship and orientation of the body in space obtains, accrues and loses its connections. The result is both and amplification and alienation of the relationship between the body and the histories of violence enfleshed by the performance. If, as Avery Gordon suggests, ghosting ushers forth edicts of history to attend to the damage to which they attest, Abraham becomes and transforms the ghosts of these violent experiences through a kinetic confrontation. ${ }^{28}$ Abraham's repeated and eradicated ghosting enacts a tragic return of a violent past that also faces reckoning. The tragic echoes of lynching in gang violence, repurposed as misogyny is addressed and mourned despite their controversial linking. Abraham's occasional low swift swiping of his hands like an inverted windshield wiper accompanied by an intentional focus or turn of focus from his head subtly swipes away a returning paradigm of violence only for it to capture his attention elsewhere. At the end of the film reduced, returned back to one, a unitary Abraham slows to a tense calm, a deceleration to an energetic stillness before a fade to black. The visual calming does not resolve the fragmentation of Abraham's querying and responsive body. He constitutes in himself a loving bridge toward further engagement via a reunified selfhood.

Frantz Fanon's third person consciousness is choreographed here in a new configuration of emerging selfhood. Fanon observes that a fixed epidermal schema, a complex social assignment of the meaning of blackness, alienates a subject from himself such that he becomes both unknown and observer to himself in a triplicate that removes "I," from "You," from an embattled, racialized "S/he." The subject looks at "himself" as if from afar served up strange to one's own gaze through the estranged, racist gaze of another. ${ }^{29}$ In this mix of this alienated self-perception, the subject is bequeathed the task of searching for an authentic self. In the Dance Response Project's Blood on The Leaves Abraham's embodiment of three selves at once dramatizes the play of alienation within a Black reality in the context of violence. The nausea of estrangement results not only racism, but also from legacies of racialized violence including that which is perpetrated within Black communities. Yet the looking is both inward and outward, and in the film the looking is his own within the context of persistent violence through history. The mourning of early 20th century lynching sounded in Holiday's activist dirge hears a fractured, disjunctive millennial echo in CMurder's rousing war-cry of casual belligerent animosity. The musical scoring forges and critiques this internal, social, and transtemporal contemplation and self- 
construction. In his triplicate apparition Abraham incorporates the darkness of annihilation while also acting out an emergence of self as a critical interlocutor to the historical and musical narrative. Such an emergence is not always romantic or utopic "fuck them other niggas" as gang violence against a rival testifies to a rowdy persistence of the perpetration of murder. Violence is never over. In dancing at the temporal intersection of violence, Abraham turns the gaze of violence upon violence. In the space of destruction and intimate annihilations, he suggests love of self as his repeated inward gaze conjures more self-attending selves. Drawing on the interpersonal trans-historical magnetism and redress of / am Sold, the triplicate selves in Blood on The Leaves address and take on violence in order to redress it with a possibility of kinder proximity. The third person consciousness becomes then not alienated from the self but engaged in a scopophilic calling of the self to the self through, despite, and instead of conditions racism, self-alienation, and annihilation. The provocation is towards an eradication of violence replaced with the thickness of a multiplying self, characterized by introspection, thick being-ness, and self-love. He expands, multiplies, and returns to himself.

Abraham and Schneider's Blood on The Leaves layers pain, conflict, sadness, and love within the self that resonates towards the viewer across the flat boundary of the screen from a-temporal digital spacelessness to socio-historically situated viewer. Even as film is understood to enact an affective response upon the viewer, Abraham's resonant feeling is also shared with himself. Though he dances alone he becomes a built in audience to his own multiple and complex displays. The tripling of music and choreography plays with and upon the gestures of Abraham's own body constructing new kinetic chords, new danced melodies, even as he acknowledges, repeats and revises violences through the musical narrative.

Kyle Abraham and Carrie Schneider collaboratively reconstruct the gaze towards loving blackness in their kinetic and visual performance of sensuous blackness seeing and seen to envision human love and loving liberation. Perhaps like Abel Meerpol and Billie Holiday in collaboration on the iconic radical 1939 protest song Strange Fruit, Abraham and Schneider strive towards a radical revisioning of blackness and discourses on race. If we emphasize the interraciality of their collaborative "looking," the resonance then with Fanon's 1967 racial structure of abjection becomes further revised. They revise white supremacist orientations of envisioning blackness by incorporating a white gaze in Schneider's camera work. Fanon's "Look a Negro!" interpellation that asserts a third person racial bodily schema becomes revised and not at all a gesture of abjection echoed strangely in Meerpol and Holiday's Strange Fruit, but a collaborative magnetic looking that casts a loving optic in and towards interracial connection against racism and racial hierarchy. Their looking in their kinetic visual play animates a theater of closeness and trust in a restructure of racialized lookings, identifications, and interactions. Thus when Schneider edits K/A's gaze to look with and upon himself at his 
own multiple engagements with (or "lookings" at) black histories and histories of black discourse, she witnesses, participates in, and accompanies his self-reflection in a collective looking and concomitant reflection of history. In an extension of racialized looking beyond binary concerns, together they also approach intimacy, alienation, and desire on various terms including race, gender, sexuality, sociality, and history.

Both Dance Response pieces offer contemporary contemplations of racial histories towards love and self-love. I am Sold supersedes historical taboos surrounding interracial and homosexual love and desire in its tender contemplation of intimacy. Intimacy is multiplied beyond dualities towards poly-amorous sociality and loving communion with four entangled hands. The kind entanglements grow. The fingers substantiate love beyond any mode of individual desire. Through a likewise multiplication of subjects, Abraham confronts the unspeakable connection between anti-black terrorism in American lynching, the celebration of murder of blacks in urban gang violence, and the disjunctive appropriation of these towards toxic Black masculinity. He entangles his own body in the interplay of histories and discourses. Abraham and Schneider's risky multiplicities in both pieces never remain discrete but meet in gestures of unity-a holding of hands and return to an engaged, unified self, Abraham broaches distances of racial antipathy and difference through increasing intimacy between multiplied bodies and offering a visual, haptic seduction of the viewer.

Abraham is an open interlocutor about his work except, typically, regarding the nature of its politics. Instead he allows the work to offer trenchant social critique and transformative provocation to the audience without rendering his own political voice towards interpretation or exegesis. The political content of the work speaks for itself in complex layers of kinetic communication and kinesthetic exhortation. And it does, but not in a way that might be familiar to followers of dance who expect protest and instruction from Black artists. Abraham's kinetic engagements with injustice spin trajectories that complicate race, racism, gender, sexuality, desire and love. The intimacy of the affective environments created in Abraham and Schneider's Dance Response Projectpromote a reconsideration of subjective inter-relationality towards personal and social transformation. The multiplicities and repetitions of the body, as many or one, address love and community. Community expands and comes together in / am Sold. Embodied in a multiplicity of one, community splits off and reunites to confront multiple histories and embodiments of violence sounded in Black music in Blood on The Leaves. As an instantiation of different overlapping discursive intraracial, and production's interracial, communities in content and context, Blood on The Leaves also expands community and intersectional interrelationality. Choreography and visual technique take up how can one be, be with, can carry all of these loving selves in transformative unity. Through tension and crisis the love of and loving self, the love of 
and loving others establish the possibility of reimagined and reformed ways of being and relationships to violent histories.

\section{Biography}

Stephanie Leigh Batiste is Associate Professor of Black Studies and English at The University of California at Santa Barbara. Her specialty areas include Black Performance Studies, African American Literature and Culture, American Studies, Race and Racism, and Cultural Studies. Batiste's research examines the operation of blackness and postcoloniality as subject positions in scholarship on race challenging the notion of the abject and the operation of subalterity. Her first book, Darkening Mirrors: Imperial Representation in Depression Era African American Performance (Duke University Press, 2011) focuses on the relationship between power and identity in black performance cultures to reimagine black subjectivity and citizenship as an engagement with dominant historical systems of thought and critical streams in American Studies.

Email: sbatiste@english.ucsb.edu

Website: http://www.blackstudies.ucsb.edu/people/stephanie-batiste

\section{Notes}

${ }^{1}$ Accessed on Vimeo.com between 2014 and 2017. The Dance Response Project has six videos available on Vimeo and carrieschneider.net. Blood on The Leaves, making seven, has since been removed from Vimeo. See also www.abrahaminmotion.org and http://carrieschneider.net/projects/danceresponse.html\#.

${ }^{2}$ Batiste, Darkening Mirrors, 176-182.

${ }^{3}$ Ibid., xi-xx.

${ }^{4}$ Ibid., 181.

${ }^{5}$ Email exchange between author and Carrie Schneider 4/11/2018.

${ }^{6}$ Conversation with Kyle Abraham, March 2016. 
${ }^{7}$ This description appears on the Dance Response Project videos on Vimeo.com https://vimeo.com/84924942.

${ }^{8}$ Ultimately the collaborations appeared art museums in Nashville and Chicago allowing the pieces' performance lives to grow as visual art. The two shared residencies at Jacob's Pillow (Becket, MA) in 2010 and On the Boards (Seattle, WA) in 2011. http://www.carrieschneider.net/biography.html

${ }^{9}$ Marks, Touch, xvii.

${ }^{10}$ Laura Mulvey articulates a scopophilic gaze that manifests, a pleasure in looking at another body as an erotic object, and an auto-eroticism, a feeling of sensuality and sex in the viewer, inspired in its original articulation by the female form. See Mulvey, "Visual Pleasure and Narrative Cinema." Here the visual attraction and imbrication results from an intense erotic gaze upon the male form.

${ }^{11}$ Barker, 12-13.

${ }^{12}$ Marks, xiii, 2.

${ }^{13}$ Ibid., 159.

${ }^{14}$ Kaciano Barbosa Gadelha attempts to provide a foundation for queer visuality online through a distant assessment of gay online dating behavior. He finds that engagements around gay desire online promote social interactivity both in online and physical space. See Gadelha, "The Persistence of Desire."

${ }^{15}$ Kaja Silverman, "Fassbinder and Lacan," 278. See also Silverman, Male Subjectivity at the Margins.

${ }^{16}$ Kyle Abraham and Carrie Schneider Dance Response Video: I am Sold, https://vimeo.com/84924942. Accessed July 2017; March 2018.

${ }^{17}$ Audre Lorde's canonical essay "Uses of the Erotic" offers a feminist reading of the power of the erotic as a force to transform society.

${ }^{18}$ James Baldwin offers a model of radical love as the only pathway away form violence, racism and imperialism towards social transformation in The Fire Next Time, 8, 43, 95-99.

${ }^{19}$ Barker, The Tactile Eye, 119.

${ }^{20}$ Fleetwood, Troubling Vision, 18, 136-8.

${ }^{21}$ West, Blood on the Leaves.

${ }^{22}$ It is very difficult to understand C-Murder's song as ironic and critical or just about verbal play, as is often accomplished in a purportedly resistant practice of claiming 
aggressive black music as also resistant to forces of black annihilation. The characteristics of the song preclude recuperation. The simultaneous violence as social glue and the insistence on the deaths of enemies constructs this social content.

${ }^{23}$ Johnson, Sounds of Solidarity, Spaces of Conflict, xiv.

${ }^{24}$ Marks, 152.

${ }^{25}$ Deger, Shimmering Screens, 89-90.

${ }^{26}$ Marks, xviii.

${ }^{27}$ Mulvey argues that the scopophilic relationship between the viewer and the screen is auto erotic per the viewer's solitary haptic relationship to the screen. Dynamic sensation occurs in her own body. See Mulvey, 46-57.

${ }^{28}$ Gordon, Ghostly Matters, xvi.

${ }^{29}$ Fanon, Black Skin, White Masks, 90-92.

\section{References}

Baldwin, James. The Fire Next Time, (c1963). First Vintage International Edition, New York: Vintage Books, 1993.

Batiste, Stephanie Leigh. Darkening Mirrors: Imperial Representation in Depression-era African American Performance. Durham [N.C.]: Duke UP, 2011.

Barker, Jennifer M. The Tactile Eye: Touch and the Cinematic Experience. Berkeley: University of California Press, 2009.

Deger, Jennifer. Shimmering Screens: Making Media in an Aboriginal Community. Minneapolis: University of Minnesota Press, 2006.

Gadelha, Kaciano Barbosa. "The Persistence of Desire: Gay Men and Online Queer Visuality," Arte y Políticas de Identidad. 15 (2016): 59-72.

Gordon, Avery. Ghostly Matters: Haunting and the Sociological Imagination. Minneapolis: University of Minnesota Press, 2008.

Fanon, Frantz. Black Skin, White Masks. 1st Ed., New ed. New York: [Berkeley, Calif.]: Grove; Distributed by Group West, 2008, 
Fleetwood, Nicole R. Troubling Vision: Performance, Visuality, and Blackness. Chicago: U of Chicago, 2011.

Johnson, Gaye Teresa. Sounds of Solidarity, Spaces of Conflict, Berkeley, University of California Press, 2013.

Lorde, Audre. Uses of the Erotic: The Erotic as Power. Out \& Out Pamphlet; No. 3. Brooklyn, N.Y.: Trumansburg, N.Y.: Out \& Out Books; Distributed by Crossing Press, 1978.

Marks, Laura U. Touch: Sensuous Theory and Multisensory Media. Minneapolis: U of Minnesota, 2002.

Mulvey, Laura. "Visual Pleasure and Narrative Cinema," Feminism and Film Theory, ed. Constance Penley, New York: Routledge, 1988. 46-57.

Silverman, Kaja. Male Subjectivity at the Margins. New York: Routledge, 1992.

. "Fassbinder and Lacan: A Reconsideration of Gaze Look and Image," in Norman Bryson, Michael Ann Holly, Keith P. F. Moxey, Visual Culture: Images and Interpretations. Hanover, NH: Wesleyan University Press, 1994.

West, Kanye. Blood on the Leaves, Yeezus, Def Jam Recordings, a division of UMG Recordings, Inc., 2013. 